\title{
Functional modulation of caecal fermentation and microbiota in rat by feeding bean husk as a dietary fibre supplement
}

\author{
H. Myint, H. Kishi, Y. Iwahashi, W. Saburi, S. Koike and Y. Kobayashi" \\ Graduate School of Agriculture, Hokkaido University, Kita 9 Nishi 9, Sapporo, Japan; kyas@anim.agr.hokudai.ac.jp
}

Received: 27 November 2017 / Accepted: 1 July 2018

(C) 2018 Wageningen Academic Publishers

OPEN ACCESS @(1)(0 RESEARCH ARTICLE

\begin{abstract}
A feeding study using rats was conducted to evaluate the utility of lablab bean husk and soya bean husk as sources of potential prebiotic fibre. Twenty 5-week-old Sprague Dawley rats were divided into 4 groups and fed one of the following diets for 3 weeks: purified diet (AIN93 G) containing 5\% cellulose (CEL), or the same diet in which cellulose was replaced by corn starch (STA), lablab bean husk (LBH), or soya bean husk (SBH). Rats were sacrificed at 8 weeks of age and caecal digesta were collected. Feed intake, body weight, anatomical parameters, and caecal ammonia level did not differ significantly among diets. Rats on LBH and SBH showed higher concentrations of caecal short-chain fatty acid and lactate than those on CEL. Rats on CEL, SBH, and LBH exhibited lower caecal indole and skatole levels. LBH yielded increased caecal abundance of Akkermansia muciniphila and Oscillibacter relatives, as demonstrated by either qPCR, MiSeq, or clone library analysis. SBH favoured the growth of lactobacilli as assessed by both qPCR and MiSeq, and favoured the growth of bifidobacteria as assessed by MiSeq. In comparison with STA, LBH and SBH yielded lower caecal abundance of bacteria related to Dorea massiliensis, as demonstrated by qPCR, MiSeq, and clone library analysis. Both types of bean husk were found to contain oligosaccharides that might selectively stimulate the growth of beneficial bacteria. Based on these results, the two species of bean husk tested are considered potentially functional for promoting the gut health of monogastric animals.
\end{abstract}

Keywords: bean husk, fermentation metabolites, gut health, microbiota

\section{Introduction}

Bean husk is an agricultural waste that is generated from the processing of beans for human consumption. The husk represents approximately $7-8 \%$ of the bean (Gnanasambandam and Proctor, 1999; Htay et al., 2014) that is not available as human food, but this byproduct is underutilised as a food ingredient for animals. However, bean husk is rich in easily digestible fibre that can boost the growth of fibre-degrading bacteria in the gastrointestinal (GI) tract of herbivorous livestock animals such as ruminants; bean husk is also used as a supplemental food ingredient, an application that takes advantage of the material's nutritional properties (Fuma et al., 2012; Ngwe et al., 2012). Therefore, bean husk has gained attention as a new possible source of functional fibre for other animals, in particular monogastrics.
Lablab bean (Dolichos lablab), commonly referred to as hyacinth bean or field bean, is a major pulse crop in South and South East Asia. Feeding with lablab bean husk has been shown to lead to the alteration of rumen flora and activity by selective stimulation of specific fibrolytic bacteria (Fuma et al., 2012), and to facilitate increased fibre digestibility in sheep (Ngwe et al., 2012). These results suggest that this material can be used as an easily digestible supplemental fibre for ruminant animals. Lablab bean husk contains cellulose and hemicellulose (Fuma et al., 2012), as well as pectic polysaccharides that incorporate arabinogalactan as a major sugar, including arabinose and rhamnose (Muralikrishna and Tharanathan, 1994). Therefore, lablab bean husk is worthy of evaluation for its possible use as a feed ingredient not only for ruminants, but also for monogastric animals. 
Soya bean (Glycine max) husk is widely used as a ruminant feed and has been proposed for use as a feed for lactating dairy cows (Ipharraguerre and Clark, 2003). Soya bean husk contains complex carbohydrates including pectin, hemicellulose, and cellulose (Karr-Lilienthal et al., 2005; Monsoor, 2005; Mullin and Xu, 2001). Specifically, the major cell wall polysaccharide in soya bean husk is galactomannan, which is composed of galactose, mannose, arabinose, and glucose (Hussein et al., 1998). Soya bean husk also has been proposed for use as an energy feed for ruminants (Ipharraguerre and Clark, 2003) based on the observation that this material modifies rumen fermentation by permitting increases in the cellulolytic microbial population in dairy cows (Belanche et al., 2012), a property also reported for lablab bean husk (Fuma et al., 2012; Ngwe et al., 2012). Soya bean husk was suggested for use as an ingredient in dog food that would not negatively affect nutrient digestion (Cole et al., 1999); previous work has shown that consumption of soya bean husk yields a decrease in the level of harmful faecal fermentation products, including sulphide and indole, along with an increase in short-chain fatty acids (SCFAs) with a concomitant reduction of faecal pH (Simpson et al., 2002). Soya bean husk feeding in pigs decreases faecal $\mathrm{pH}$ and ammonia emission without negatively affecting growth performance (Wang et al., 2009); the non-starch polysaccharide in soya bean husk is believed to promote the activity of lactobacilli and bifidobacteria that utilise ammonia. Recently, soya bean husk fed to piglets has been reported to improve intestinal anatomical morphology and microbial community due to decreased proliferation of Escherichia coli (Pascoal et al., 2015).

Bean husk is considered an efficient source of soluble and insoluble dietary fibre that could be utilised as a feed supplement for the improvement of GI health of monogastric animals. Dietary fibres, which include nonstarch polysaccharides (cellulose, hemicelluloses, pectin, gums, and lignin) and oligosaccharides, possess water- and oil-retaining capacity, bulk, and swelling power, leading to physiologically favourable effects. These effects can include decreases in blood cholesterol and glucose levels, and maintenance of GI health (Tungland and Meyer, 2002). Dietary fibre resists digestion in the small intestine; upon delivery to the large intestine, this fibre is believed to contribute to the modulation of the GI microbiota by selectively stimulating the growth and/or activity of specific bacteria that can improve host health (Gibson and Roberfroid, 1995). Therefore, supplementation of animal diets with bean husk that contains such beneficial fibre is expected to stimulate the generation of favourable fermentation products in the GI tract through microbial modulation. Such intestinal microbiota-mediated functionality of bean husk in monogastric animals is still under investigation. The objective of the present study was to evaluate the utility of lablab bean husk and soya bean husk in caecal fermentation and microbial community regulation in rats; these results are expected to provide insights into the future development of functional foods for monogastric animals.

\section{Materials and methods}

\section{Animals and diets}

This feeding experiment was conducted using twenty male Sprague Dawley rats (Japan SLC, Inc., Hamamatsu, Japan), aged 5 weeks. Rats were housed individually in plastic cages in an environmentally controlled room maintained at $23^{\circ} \mathrm{C}$ with a $12 \mathrm{~h} / 12 \mathrm{~h}$ light-dark cycle (lights on from 12:0024:00) and 55-60\% relative humidity. Rats were divided into four groups ( $\mathrm{n}=5$ per group) with an average body weight of $159.1 \pm 5.1 \mathrm{~g}$. Diet and water were provided ad libitum. One group was given a purified diet (AIN 93G; CLEA Japan, Inc., Tokyo. Japan) that contains $5 \%$ cellulose powder as a fibre source. This feed (designated CEL) was used as the control diet. The other three groups were given the same purified diet in which the $5 \%$ cellulose was replaced by either corn starch (STA), lablab bean husk (LBH), or soya bean husk (SBH). STA did not contain any fibre source and was regarded as a negative control. Corn starch was purchased from Wako (Osaka, Japan). Lablab bean husk was kindly provided by Professor Tin Ngwe (University of Veterinary Science, Yezin, Myanmar), and was obtained from a local pulse processing plant (Yezin, Nay Pyi Taw, Myanmar) where the beans had been soaked in water and de-hulled by hand. Soya bean husk (Japanese product) was obtained through ZEN-NOH (Tokyo, Japan). All of the rats were measured for body weight weekly and for feed intake daily; the feed conversion ratios were calculated from these data. After 3 weeks, rats were euthanised with xylanzine $\mathrm{HCl}$. At necropsy, GI segments (oesophagus, stomach, small intestine, caecum, and colon) and their contents were harvested and weighed. Caecal digesta was sampled and stored at $-80{ }^{\circ} \mathrm{C}$ for the analysis of fermentation products and microbiota. Blood was sampled from the heart by syringe, centrifuged to obtain plasma, and frozen as above. The animal experiment was carried out in compliance with the Guidelines for Animal Experiments, Hokkaido University (2007) and the Act on Welfare and Management of Animal (2005).

\section{Chemical analyses of bean husks}

The chemical composition of both types of bean husk was analysed in triplicate, including testing for dry matter, crude protein, crude fat, and crude ash using the Association of Official Analytic Chemists methods (AOAC, 1990). Neutral detergent fibre (NDF) and acid detergent fibre (ADF) were determined using a fibre analyser (A200, ANKOM, Fairport, NY). Heat stable amylase was used in the NDF determination; the resulting values are inclusive of residual 
ash. Analysis of acid detergent lignin was also performed (Goering and Van Soest, 1975). For sugar analysis, the soluble fraction of the bean husk was obtained by water extraction (100 g husk per litre water for $24 \mathrm{~h}$ ). The resulting extract was freeze-dried; a 500-mg aliquot was dissolved in $1.2 \mathrm{ml}$ of water and the sugar composition was analysed by thin-layer chromatography (TLC) using a silica gel $60 \mathrm{~F}_{254}$ plate (Merck, Darmstadt, Germany). The TLC developing solvent consisted of isopropanol/1-butanol/water (12:3:4, $\mathrm{v} / \mathrm{v} / \mathrm{v})$. Maltooligosaccharide mixture $(2 \% \mathrm{w} / \mathrm{v})$ was used as a standard. Sugars were visualised by spraying the TLC plate with anisaldehyde-sulfuric acid reagent (1\% anisaldehyde and $2 \%$ sulfuric acid in acetic acid) followed by heating of the plate. To purify the oligosaccharides included in the water extract, the extract was separated by gel-filtration column chromatography using a Bio-gel P-2 Extra Fine column (Bio-Rad, Hercules, CA, USA); $1.5 \mathrm{~cm}$ i.d. $100 \mathrm{~cm}$ ). Water was used as mobile phase with a flow rate of $3 \mathrm{ml} / \mathrm{h}$. 100 fractions (4 $\mathrm{ml}$ per tube) were collected, and sugar concentrations were measured by the phenol-sulfuric acid method (Dubois et al., 1956) using glucose as a standard. Fractions containing oligosaccharides, including fractions S1, S2, S3, L1, L2, and L3 (see Results), were used for further analyses. Molecular masses of the purified oligosaccharides were analysed by electrospray ionisation mass spectrometry (ESI-MS) using an Exactive mass spectrometer (Thermo Fisher Scientific, Waltham, MA, USA). Structural characterisation of fractions $\mathrm{L} 1$ and L2 was performed by dissolving the samples in $\mathrm{D}_{2} \mathrm{O}$ and obtaining ${ }^{13} \mathrm{C}$-NMR spectra using a Bruker AMX500 NMR spectrometer (Bruker, Billercia, MA, USA).

\section{Measurement of blood parameters and caecal fermentation products}

Blood plasma was analysed for glucose and total cholesterol by using commercially available kits (Wako). Caecal digesta $(1 \mathrm{~g})$ was suspended in saline $(5 \mathrm{ml})$ and vortexed, and the mixture was then centrifuged $\left(4{ }^{\circ} \mathrm{C}, 7,800 \times \mathrm{g}, 5 \mathrm{~min}\right)$. The resulting supernatant was used to measure $\mathrm{pH}$ by electrode (F-51, Horiba, Kyoto, Japan), and also subjected to the analysis of SCFA, lactate, succinate, ammonia, indole, and skatole concentrations. SCFA was determined by gas chromatography (GC-14B; Shimadzu, Kyoto, Japan) equipped with $0.53 \mathrm{~mm} \times 30 \mathrm{~m}$ capillary column (ULBON HR-20M; Shimadzu) as previously reported (Suto, 1973). D-lactate, L-lactate, and succinate were measured by D/L Lactic Acid Assay Kits and Succinic Acid Assay Kits (Megazyme, Bray, Ireland) according to manufacturer's instructions for the respective kits. Ammonia nitrogen $\left(\mathrm{NH}_{3}-\mathrm{N}\right)$ was measured by the phenol-hypochloride reaction method (Weatherburn, 1967) using a microplate reader (ARVO MX; Perkin Elmer, Waltham, MA, USA) at $660 \mathrm{~nm}$. Assays for indole and skatole were carried out by colorimetric methods (Walstra et al., 1999).

\section{Microbiota analysis by qPCR}

Bacterial DNA from each caecal sample was extracted using the repeated bead beating plus column method (Yu and Morrison, 2004) with a QIAamp DNA Stool Mini Kit (Qiagen, Hilden, Germany). Purified DNA was diluted appropriately before further analysis (for qPCR and $16 \mathrm{~S}$ rDNA clone library). Bacterial communities were quantitatively characterised by real-time PCR assays with species/group-specific primers for the representative groups, including total bacteria, total lactobacilli, different Lactobacillus species (Lactobacillus acidophilus, Lactobacillus gasseri, Lactobacillus johnsonii, Lactobacillus reuteri), total bifidobacteria, Faecalibacterium prausnitzii, Eubacterium hallii, Clostridium coccoidesEubacterium rectale group, Bacteroides-PrevotellaPorphyromonas group (Rinttila et al., 2004), E. coli, and Clostridium perfringens, using a LightCycler 480 realtime PCR system (Roche Applied Science, Mannheim, Germany), as previously reported (Myint et al., 2017). Primers for OTU 4, OTU 5, OTU 6, and OTU 10 (detected in the 16S rDNA library; see Results) were newly designed. The sequences of the primers $\left(5^{\prime}-3^{\prime}\right)$ for these assays were F: ACGCGAAGAACCTTACCTGA and R: GCACGTGTGTAGCCCTGG for OTU 4 (Dorea massiliensis), F: ACGTGACGGTACCTGGA and R: GGGACACAGTTTTGAGAG for OTU 5 (Oscillibacter relatives), F: GGACTCGCGTCCGATTAGT and R: ACTGGTGTTCCTCCCCATC for OTU 6 (Ruminococcus bromii), and F: CAGCACGTGAAGGTGGGGAC and R: CCTTGCGGTTGGCTTCAGAT for OTU 10 (Akkermansia muciniphila). Primer specificity, quantification range, and other validation reactions were performed as described by Koike et al. (2007). Results from samples were averaged among the animals in each dietary group and reported as a log value (gene copy number per g digesta) for total bacteria and also as a relative abundance (\%) of each species or group in total bacteria.

\section{Microbiota analysis by $16 \mathrm{~S}$ rDNA clone library}

Bacterial DNA from each caecal digesta was amplified by PCR with the primers 27F (AGAGTTTGATCATGGCTCAGA) and 1525R (AAGGAGGTGWTCCARCC). The reaction mixture for library construction consisted of $2.5 \mu \mathrm{l}$ of 10 Ex-Taq buffer, $2.0 \mu \mathrm{l}$ of $2 \mathrm{mM}$ dNTP, $0.5 \mu \mathrm{l}$ of each primer, $18.375 \mu \mathrm{l}$ of water, $0.125 \mu \mathrm{l}$ of Takara Ex-Taq polymerase, and $1.0 \mu \mathrm{l}$ of template DNA (10 $\mathrm{ng} / \mu \mathrm{l})$. PCR conditions were as follows: initial denaturation at $94{ }^{\circ} \mathrm{C}$ for $0.5 \mathrm{~min}$, annealing at $58{ }^{\circ} \mathrm{C}$ for $0.5 \mathrm{~min}$, and extension at $72{ }^{\circ} \mathrm{C}$ for $1.5 \mathrm{~min}$. Final extension was performed at $72{ }^{\circ} \mathrm{C}$ for $7 \mathrm{~min}$. The PCR product was purified by a QIAquick Gel Extraction Kit (Qiagen) after performing agarose gel electrophoresis, then ligated with pGEM-T Easy Vector (Promega, Madison, WI, USA) and transformed into E. coli JM109 (Nippon Gene, Tokyo, Japan). White colonies 
that developed on ampicillin- and Xgal-containing LuriaBertani plates were employed for plasmid isolation using a QIAprep Spin Miniprep Kit (Qiagen); the purified plasmid DNA was subjected to sequence analysis (TAKARA, Shiga, Japan). Sequence classification was conducted using Mothur ver. 1.29 software (Schloss et al., 2009). After removal of the chimeric sequences, sequences sharing $\geq 97 \%$ identity were grouped into operational taxonomic units (OTUs). The nucleotide sequences were compared with known sequences in the GenBank database using BLASTn (http:// blast.ncbi.nlm.nih.gov/Blast.cgi) to obtain similarity values. The Clustal X program (http://www.clustal.org) for multiple sequence alignment and phylogenetic analysis was used. A neighbour-joining tree with a Kimura-2 correction was created (Collins et al., 1994). The sequences obtained were deposited in the DDBJ nucleotide sequence database under the accession numbers AB969309 through AB969665.

\section{Microbiota analysis by MiSeq}

For the comprehensive analysis of microbial communities, MiSeq analysis was performed. Hypervariable V3-V4 regions of $16 \mathrm{~S}$ rDNA were amplified by using the universal bacterial primer set (Herlemann et al., 2011), consisting of S-D-Bact0341-b-S-17 (CCTACGGGNGGCWGCAG) and S-D-Bact0785-a-A-21 (GACTACHVGGGTATCTAATCC), where $\mathrm{N}$ stands for $\mathrm{A}, \mathrm{C}, \mathrm{G}$ or $\mathrm{T}, \mathrm{W}$ for $\mathrm{A}$ or $\mathrm{T}, \mathrm{H}$ for $\mathrm{A}, \mathrm{T}$ or $\mathrm{C}$, and $\mathrm{V}$ for $\mathrm{A}, \mathrm{C}$ or $\mathrm{G}$. The PCR reaction mixture $(50 \mu \mathrm{l})$ contained $10 \mu \mathrm{l}$ of $5^{\prime}$ PrimeSTAR buffer, $4.0 \mu \mathrm{l}$ of dNTP, $1.0 \mu \mathrm{l}$ of each primer, $32.5 \mu \mathrm{l}$ of water, $0.5 \mu \mathrm{l}$ of PrimeSTAR polymerase TAKARA), and $1.0 \mu \mathrm{l}$ of template DNA as used for clone library analysis. PCR reaction conditions (30 cycles) were as follows: denaturation at $98^{\circ} \mathrm{C}$ for $10 \mathrm{~s}$, annealing at $55^{\circ} \mathrm{C}$ for $15 \mathrm{~s}$, and extension at $72^{\circ} \mathrm{C}$ for $30 \mathrm{~s}$. Following amplification, DNA was purified using a High Pure PCR Product Purification Kit (Roche) and sequenced (Illumina Miseq 2000, San Diego, CA, USA). Raw Illumina fastq files were demultiplexed, qualitatively checked, and analysed by Quantitative Insights into Microbial Ecology (QIIME v1.9.0) as described previously (Caporaso et al., 2010).

\section{Statistical analysis}

All data were analysed by a one-way analysis of variance (ANOVA). Tukey's procedure for multiple comparison was used to resolve differences among treatment means by using SPSS 16.0 software (SPSS, Chicago, IL, USA). Differences were considered to be significant if $P<0.05$ and trend if $P<0.10$.

\section{Results}

\section{Nutritional composition of bean husk}

Chemical composition of the two different types of bean husk tested is shown in Table 1. Insoluble dietary fibre, represented by cellulose and hemicellulose, predominated in both types of bean husk. Non-fibrous carbohydrates, consisting of soluble components such as starch, soluble sugars, and soluble fibres, accounted for $23.6 \%$ in lablab bean husk and $24.0 \%$ in soya bean husk. TLC analysis indicated the presence of three different oligosaccharides in each type of husk (denoted as L1, L2, and L3 for lablab bean husk, and S1, S2 and S3 for soya bean husk, with respective degrees of polymerisation as shown in Figure 1). After purification by gel-filtration, the molecular mass of the individual oligosaccharides in sodiated form, determined by ESI-MS, were estimated as follows: L1 and S1 had the same mass of $504 \mathrm{Da}$, while L2 and S2 shared the same mass of $666 \mathrm{Da}$. L3 and S3, whose molecular mass was estimated as $794 \mathrm{Da}$, could not be further analysed, presumably due to complexity of their structure. The ${ }^{13} \mathrm{C}-\mathrm{NMR}$ spectra of L1 and $\mathrm{L} 2$ coincided exactly with those of authentic raffinose and stachyose, respectively. Therefore, L1 and L2 were identified as raffinose and stachyose, respectively. Lablab bean husk was found to contain $0.24 \%$ oligosaccharides, in which raffinose $(0.04 \%)$, stachyose $(0.12 \%)$, and unknown oligosaccharides $(0.1 \%)$ were constituents. In the same manner, soya bean husk was found to contain $0.26 \%$ oligosaccharides, in which raffinose $(0.03 \%)$, stachyose $(0.2 \%)$, and unknown oligosaccharides $(0.03 \%)$ were constituents.

Table 1. Chemical composition of bean husk used.

\begin{tabular}{lcc} 
& Lablab bean husk & Soya bean husk \\
& & \\
Dry matter (\%) & 92.0 & 91.0 \\
$\%$ in dry matter & & \\
Crude ash & 3.3 & 4.5 \\
Crude protein & 5.9 & 9.2 \\
Ether extract & 1.2 & 1.4 \\
Carbohydrate & & \\
Cellulose ${ }^{1}$ & 52.0 & 46.8 \\
Hemicellulose ${ }^{2}$ & 13.8 & 14.0 \\
Lignin & 0.2 & 0.2 \\
Non fibrous carbohydrate ${ }^{3}$ & 23.6 & 24.0 \\
Raffinose & 0.1 & 0.1 \\
Stachyose & 0.1 & 0.2 \\
\hline${ }^{1}$ Calculated as acid detergent fibre - acid detergent lignin. \\
${ }^{2}$ Calculated as neutral detergent fibre - acid detergent fibre. \\
${ }^{3}$ Calculated as 100 - (neutral detergent fibre + ash + protein + fat).
\end{tabular}




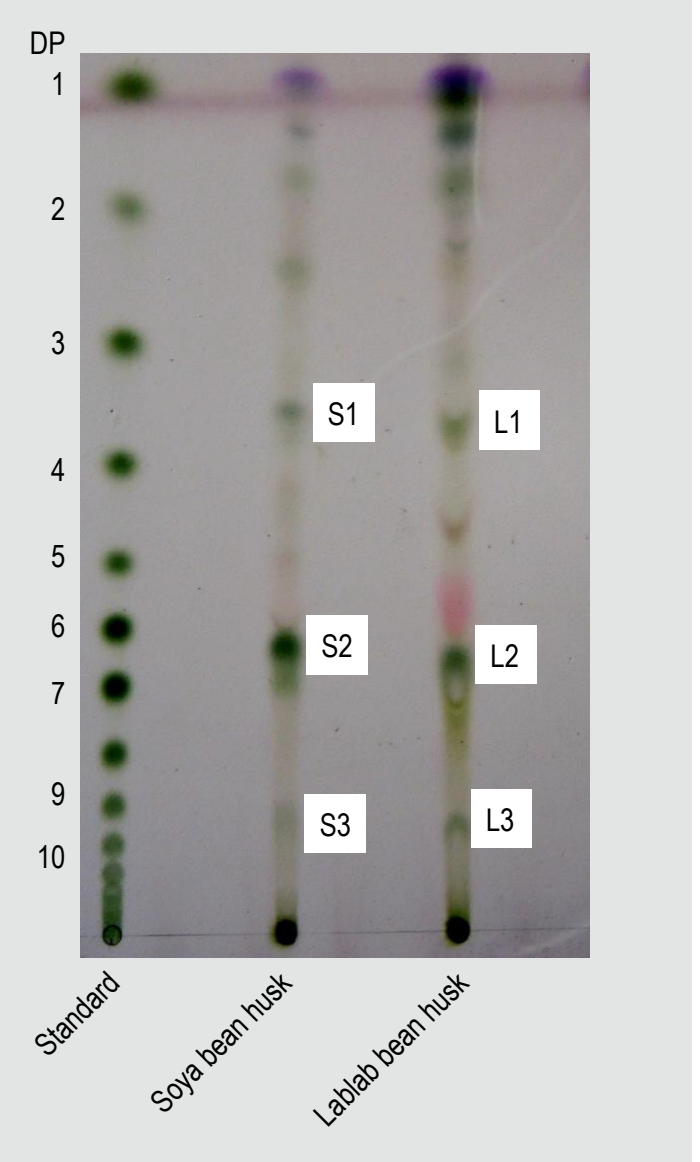

Figure 1. Thin-layer chromatography of soluble sugars from soya bean and lablab bean husks. L1, L2, L3, S1, S2, and S3 are prominent oligosaccharide fractions. DP = degree of polymerisation.

\section{Growth and caecal characteristics of rats}

Growth performance and caecal fermentation profiles are summarised in Table 2. For animals maintained for 3 weeks on the diets, no significant difference was found among the groups for feed intake, body weight gain, feed conversion ratio (all in Table 2), or weights of GI segments, contents, and internal organs (data not shown). Rats fed LBH and SBH showed lower $(P<0.05)$ caecal pH than those fed CEL and STA. The total SCFA concentration in the caecum $(P<0.05)$ was elevated in both the LBH and SBH groups compared to those in the CEL and STA groups. Similarly, the caecal acetate concentration was higher $(P<0.05)$ in LBH and SBH than in CEL and STA. The butyrate concentration in SBH was higher $(P<0.05)$ than that in CEL and STA, but did not differ from that in LBH; butyrate in LBH was higher $(P<0.05)$ than that in STA but did not differ from that in CEL. Total lactate concentration was higher in SBH and STA than in CEL, an effect that was largely due to the higher concentration $(P<0.05)$ of L-lactate. Succinate concentration in SBH was the highest among the groups and significantly higher $(P<0.05)$ than those in CEL and STA, but did not differ from that in LBH. Ammonia concentration did not differ among the groups. Rats fed STA showed the highest concentration of indole and skatole among the groups. For indole, LBH-fed rats exhibited the lowest levels, followed by CEL and then SBH. However the SBH effect on indole did not achieve significance. Skatole concentrations were lowest in rats fed LBH followed by CEL and SBH, and all of these were lower $(P<0.05)$ than STA.

\section{Microbiota}

A phylogenetic tree of clones derived from the bacterial $16 \mathrm{~S}$ rDNA clone library analysis is shown in Figure 2. A total of 503 clones having nearly full-length $16 \mathrm{~S}$ rDNA sequences were obtained and formed 39 OTUs. Lactobacillales, clostridial cluster IV, and clostridial cluster XIVa were the major clusters, to which 434 of 503 clones and 29 of 39 OTUs belonged. Bacteria belonging to OTU 4 ( $D$. massiliensis) were frequently detected in STA (23 of total 27 clones in OTU 4) but not in LBH or SBH. Bacteria belonging to OTU 5 (Oscillibacter relatives) were frequently seen in LBH and CEL (15 and 11 of total 26 clones, respectively) but not in SBH or STA. OTU 6 (R. bromii) was detected in CEL, $\mathrm{LBH}$, and SBH, but not in STA. OTU 10 (A. muciniphila) was detected only in LBH and SBH (4 and 2 of total 6 clones, respectively).

New qPCR assays for OTU 4 (D. massiliensis), OTU 5 (Oscillibacter relatives), OTU 6 (R. bromii), and OTU 10 (A. muciniphila) were successfully established with amplification efficiencies of 1.866-1.982 within ranges of $10^{2}-10^{9}$ copies of the respective target DNA. Each primer set had specificity sufficient to identify the target bacteria, as validated by mini-clone library sequencing (24-72 clones for each exhibited $100 \%$ identity in sequence). The qPCR assay values for representative caecal bacteria are shown in Table 3. The Lactobacillus group was the dominant bacterial taxon in the caecal digesta. In comparison with CEL and STA, SBH showed a higher $(P<0.05)$ proportion of total lactobacilli, L. acidophilus, and $L$. reuteri, but proportions in SBH did not differ significantly from those in LBH. Rats fed LBH had higher $(P<0.05)$ abundance of $A$. muciniphila than those fed CEL and STA. However, the abundance of A. muciniphila did not differ significantly between rats fed LBH or SBH. LBH also showed a higher $(P<0.05)$ proportion of bacteria belonging to OTU 5 (Oscillibacter relatives) in comparison with STA and SBH, but this proportion did not differ from that with CEL. Rats fed on STA showed a higher $(P<0.05)$ proportion of $D$. massiliensis compared to the rats fed LBH or SBH. However this proportion did not differ significantly from that in rats fed CEL. The abundance of total bacteria, L. gasseri, L. johnsonii, F. prausnitzii, E. hallii, total bifidobacteria, R. bromii, E. coli, BacteroidesPrevotella-Porphyromonas group, and C. coccoides-E. rectale group were not affected by diets. 
Table 2. Growth performance and caecal fermentation products of rats fed experimental diets (Mean values with standard deviation $(S D))^{1,2}$

\begin{tabular}{|c|c|c|c|c|c|c|c|c|}
\hline \multirow[t]{2}{*}{ Parameters } & \multicolumn{2}{|l|}{ CEL } & \multicolumn{2}{|l|}{ STA } & \multicolumn{2}{|l|}{ LBH } & \multicolumn{2}{|l|}{ SBH } \\
\hline & mean & SD & mean & SD & mean & SD & mean & SD \\
\hline Feed intake (g) & 426.8 & 16.5 & 420.8 & 8.4 & 459.0 & 19.8 & 442.1 & 27.4 \\
\hline Initial body weight (g) & 159.3 & 5.3 & 158.7 & 6.4 & 159.3 & 5.5 & 159.3 & 5.1 \\
\hline Body weight gain (g) & 153.0 & 7.2 & 157.8 & 24.3 & 170.0 & 12.7 & 173.1 & 11.6 \\
\hline Food conversion ratio $(\mathrm{g} / \mathrm{g})$ & 2.7 & 1.0 & 2.7 & 1.0 & 2.7 & 1.0 & 2.6 & 0.9 \\
\hline \multicolumn{9}{|l|}{ Caecal fermentation profile } \\
\hline $\mathrm{pH}$ & $7.7^{\mathrm{a}}$ & 0.4 & $7.8^{\mathrm{a}}$ & 0.4 & $7.3^{b}$ & 0.2 & $7.3^{b}$ & 0.2 \\
\hline \multicolumn{9}{|l|}{ Short chain fatty acids } \\
\hline Acetate $(\mu \mathrm{mol} / \mathrm{g}$ digesta) & $26.3^{b}$ & 4.4 & $27.5^{\mathrm{b}}$ & 3.1 & $34.4^{\mathrm{a}}$ & 2.8 & $33.8^{\mathrm{a}}$ & 2.8 \\
\hline Propionate ( $\mu \mathrm{mol} / \mathrm{g}$ digesta) & 8.4 & 1.3 & 8.1 & 5.5 & 9.3 & 2.2 & 8.5 & 0.4 \\
\hline Butyrate ( $\mu \mathrm{mol} / \mathrm{g}$ digesta) & $5.9^{\mathrm{bc}}$ & 1.3 & $4.2^{c}$ & 2.7 & $7.8^{\mathrm{ab}}$ & 0.9 & $9.7^{a}$ & 0.6 \\
\hline Total SCFA ( $\mu \mathrm{mol} / \mathrm{g}$ digesta) & $42.9^{b}$ & 6.6 & $40.5^{b}$ & 8.6 & $57.4^{\mathrm{a}}$ & 10.2 & $54.4^{\mathrm{a}}$ & 3.4 \\
\hline \multicolumn{9}{|l|}{ Lactate } \\
\hline D-lactate ( $\mu \mathrm{mol} / \mathrm{g}$ digesta) & 1.7 & 2.1 & 3.4 & 1.6 & 3.7 & 1.1 & 4.0 & 1.5 \\
\hline L-lactate ( $\mu \mathrm{mol} / \mathrm{g}$ digesta) & $2.7^{b}$ & 1.3 & $5.4^{\mathrm{a}}$ & 1.3 & $4.6^{\mathrm{ab}}$ & 1.1 & $5.2^{\mathrm{a}}$ & 1.7 \\
\hline $\begin{array}{l}\text { Total lactate }(\mu \mathrm{mol} / \mathrm{g} \\
\text { digesta) }\end{array}$ & $4.4^{\mathrm{b}}$ & 2.6 & $8.9^{a}$ & 2.5 & $8.4^{\mathrm{ab}}$ & 2.0 & $9.2^{\mathrm{a}}$ & 2.6 \\
\hline Succinate $(\mu \mathrm{mol} / \mathrm{g}$ digesta) & $0.1^{b}$ & 0.2 & $0.3^{b}$ & 0.5 & $1.1^{\mathrm{ab}}$ & 1.0 & $2.1^{\mathrm{a}}$ & 1.7 \\
\hline Ammonia ( $\mu \mathrm{gN} / \mathrm{g}$ digesta) & 82.1 & 27 & 98.7 & 25.4 & 90.1 & 27.6 & 61.1 & 39.2 \\
\hline Indole ( $\mu \mathrm{g} / \mathrm{g}$ digesta) & $12.8^{b c}$ & 3.1 & $21.7^{a}$ & 2.5 & $11.3^{c}$ & 1.6 & $16.6^{\mathrm{ab}}$ & 2.4 \\
\hline Skatole ( $\mu \mathrm{g} / \mathrm{g}$ digesta) & $71.2^{b}$ & 24.5 & $174.3^{\mathrm{a}}$ & 31.8 & $64.5^{b}$ & 12.3 & $94.1^{b}$ & 29.3 \\
\hline
\end{tabular}

After quality filtering of the MiSeq data, a total of 1,011,982 sequence reads (CEL: 234987, STA: 290834, LBH: 251263, SBH: 234898) remained from 20 samples. Alpha diversity indices including Chao 1, observed species, Shannon, and phylogenetic diversity, and relative abundance of microbial taxa at phylum and genus level $(>0.01 \%)$ are shown in Table 4. No difference was found among the groups for alpha diversity indices. The number of observed species ranged from 441-603. At the phylum level, rats fed SBH showed a higher $(P<0.05)$ abundance of Actinobacteria than those fed CEL or STA, but the value in SBH did not differ significantly from that in LBH. Within the Actinobacteria phylum, members of the genus Bifidobacteria showed different abundances, with LBH and SBH showing higher $(P<0.05)$ abundance than CEL and STA. The relative abundance of Bacteroidetes did not differ among the diet groups. However, rats fed LBH or SBH showed higher $(P<0.05)$ abundances of genus Prevotella than did those fed CEL or STA. STA showed higher $(P<0.05)$ relative abundance of unclassified Rikenellaceae than did LBH and SBH, but the value did not differ significantly from that of CEL. Firmicutes was the most abundant bacterial phylum detected in the caecum of the rats. In comparison with CEL, LBH showed lower $(P<0.05)$ abundance of Firmicutes, but the value did not differ significantly from that of STA and SBH. Within this phylum, Lactobacillus was highest $(P<0.05)$ in SBH in terms of relative abundance. STA showed higher $(P<0.05)$ relative abundance of genus Dorea than did $\mathrm{LBH}$ and $\mathrm{SBH}$, but the STA value did not differ significantly from that of CEL. The relative abundance of unclassified Ruminococcaceae was found to be higher $(P<0.05)$ in CEL than in SBH, but the value was not significantly different from that in LBH or STA. Rats fed LBH had a higher $(P<0.05)$ abundance of phylum Verrucomicrobia than did rats fed CEL and STA, but LBH and SBH did not differ significantly for this parameter. Almost all phylum Verrucomicrobia were constituted by genus Akkermansia, the proportion of which was higher $(P<0.05)$ in $\mathrm{LBH}$ than in CEL and STA. 


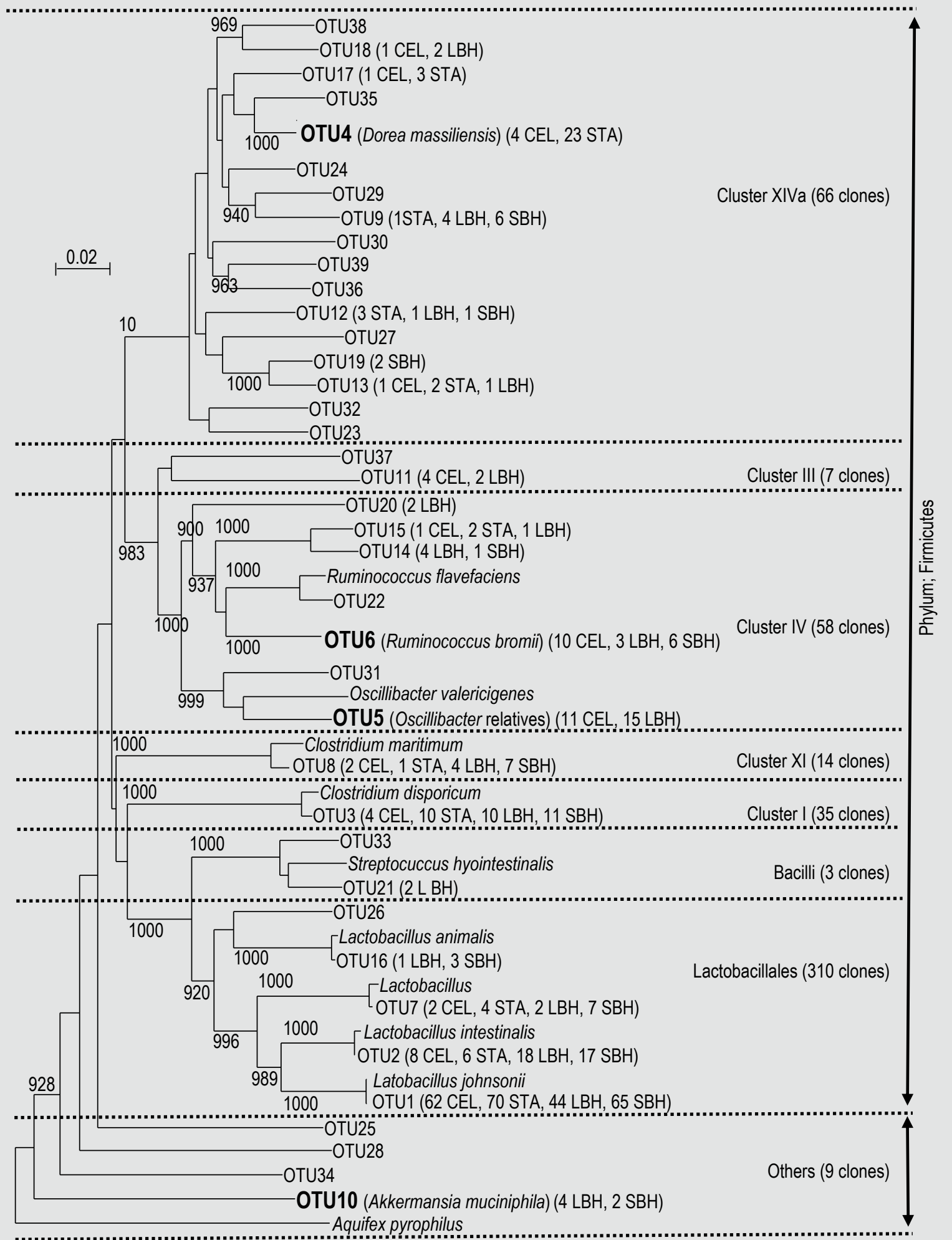

Figure 2. Phylogenetic clustering of caecal bacterial $16 \mathrm{~S}$ rDNA clone sequences of rats fed experimental diets: CEL = AIN $93 \mathrm{G}$ purified diet containing $5 \%$ cellulose; STA = negative control diet in which cellulose was replaced by corn starch; LBH = treatment diet in which cellulose was replaced by lablab bean husk, SBH = treatment diet in which cellulose was replaced by soya bean husk. Clones having $>97 \%$ sequence identity were considered to belong to a distinct operational taxonomic unit (OTU); the number of clones in each OTU is indicated in brackets. OTUs employed for qPCR results are shown in bold. The horizontal bar represents nucleotide substitutions per sequence position. 
Table 3. Caecal bacterial species and groups (mean + standard deviation (SD)) in rats fed experimental diets (analysed by realtime PCR). ${ }^{1,2}$

\begin{tabular}{|c|c|c|c|c|c|c|c|c|}
\hline \multirow[t]{2}{*}{ Species/group } & \multicolumn{2}{|l|}{ CEL } & \multicolumn{2}{|l|}{ STA } & \multicolumn{2}{|l|}{ LBH } & \multicolumn{2}{|l|}{ SBH } \\
\hline & mean & SD & mean & SD & mean & SD & mean & SD \\
\hline Total bacteria (log copy/g digesta) & 10.9 & 0.2 & 11.1 & 0.1 & 10.5 & 0.1 & 10.5 & 0.2 \\
\hline \multicolumn{9}{|l|}{ Proportion (relative \% in total bacteria) } \\
\hline Total lactobacilli & $24.6^{b}$ & 10.7 & $27.5^{b}$ & 8.4 & $32.5^{\mathrm{ab}}$ & 7.1 & $56.6^{\mathrm{a}}$ & 4.3 \\
\hline Lactobacillus acidophilus & $0.2^{b}$ & 0.1 & $0.2^{b}$ & 0.1 & $0.5^{\mathrm{ab}}$ & 0.1 & $1.3^{\mathrm{a}}$ & 0.4 \\
\hline Lactobacillus gasseri & $9 \mathrm{E}^{-6}$ & $5 E^{-6}$ & 0.00001 & $5 \mathrm{E}^{-6}$ & 0.00001 & $1 \mathrm{E}^{-6}$ & 0.00001 & $4 \mathrm{E}^{-6}$ \\
\hline Lactobacillus johnsonii & 4.1 & 1.6 & 3.5 & 1.5 & 3.8 & 0.8 & 5.2 & 1.2 \\
\hline Lactobacillus reuteri & $0.6^{b}$ & 0.3 & $0.5^{b}$ & 0.1 & $1.4^{\mathrm{ab}}$ & 0.7 & $2.2^{\mathrm{a}}$ & 0.8 \\
\hline Faecalibacterium prausnitzii & 0.1 & 0.0 & 0.0 & 0.0 & 0.0 & 0.0 & 0.0 & 0.0 \\
\hline Eubacterium hallii & 0.0009 & 0.0 & 0.0006 & 0.0 & 0.0004 & 0.0 & 0.02 & 0.01 \\
\hline Total bifidobacteria & 0.06 & 0.02 & 0.03 & 0.01 & 0.03 & 0.01 & 0.01 & 0.002 \\
\hline OTU 10 (Akkermansia muciniphila) & $3.5^{b}$ & 1.6 & $4.1^{b}$ & 1.4 & $28.3^{a}$ & 4.5 & $15.9^{\mathrm{ab}}$ & 10.1 \\
\hline OTU 4 (Dorea massiliensis) & $3.2^{\mathrm{ab}}$ & 1.0 & $6.9^{\mathrm{a}}$ & 1.5 & $2.2^{b}$ & 0.2 & $1.8^{b}$ & 0.2 \\
\hline OTU 5 (Oscillibacter relatives) & $12.0^{\mathrm{ab}}$ & 3.5 & $0.0^{b}$ & 0.0 & $21.5^{\mathrm{a}}$ & 3.2 & $2.0^{b}$ & 0.5 \\
\hline OTU 6 (Ruminococcus bromii) & 4.2 & 1.1 & 3.0 & 0.7 & 4.5 & 1.0 & 3.1 & 0.8 \\
\hline Eschericheria coli & 0.6 & 0.5 & 0.7 & 0.5 & 0.2 & 0.1 & 0.03 & 0.01 \\
\hline Bacteroidetes-Prevotella- & 0.5 & 0.4 & 1.3 & 0.7 & 0.2 & 0.1 & 0.02 & 0.01 \\
\hline \multicolumn{9}{|l|}{ Porphylomonus group } \\
\hline $\begin{array}{l}\text { Clostridium coccoides-Eubacterium } \\
\text { rectale group }\end{array}$ & 10.2 & 3.2 & 12.6 & 2.8 & 5.0 & 0.8 & 2.9 & 1.7 \\
\hline
\end{tabular}

\section{Discussion and conclusions}

The addition of $5 \%$ bean husk to the diet of rats had no significant effect on feed intake, body weight, feed conversion ratio, or anatomical data, including the weights of GI tract segments and contents. Blood parameters such as glucose and cholesterol were within normal ranges and not different among the groups maintained on distinct diets (data not shown). Therefore, either of two different types of bean husk is proposed for use as a feed ingredient for monogastric animals; supplementation of rat feed with 5\% bean husk did not exhibit detrimental effects on growth performance or general health status.

Although the husk of different beans contains similar amount of dietary fibre, their functions may be inherently different in the caecum of rats, due to possible difference of physicochemical characteristics of components of dietary fibre between two types of bean husk. Those could be type of pectin, amylose to amylopectin ratio and others. In the meantime, the presence of potent negative growth factor in tested bean husk is also to be clarified in further evaluations. Another important factor is oligosaccharide in the tested bean husk. Separation of soluble sugars revealed the presence of oligosaccharides, including raffinose, stachyose, and others, in the two tested species of bean husk. In comparison with lablab bean husk, soya bean husk contained higher level of stachyose, which is a nonreducing tetrasaccharide composed of two galactoses, one glucose, and one fructose. Lablab bean husk feeding yielded distinct effects in the caecum such as increases of SCFAs, especially acetate; soya bean husk feeding yielded similar effects but with a distinguishing feature of increased lactate. The increases of these beneficial organic acids with both types of bean husk were probably the main reason for the decrease of $\mathrm{pH}$, reflecting fermentation of bean husk fibre in the caecum. The increase in the concentration of acetate by lablab bean husk feeding might correspond to the increase in the proportion of acetate-producing bacteria, particularly Akkermansia, that was detected by the MiSeq, clone library, and qPCR analyses; a similar effect on bifidobacteria was supported only by the MiSeq data. Previous studies in obese mice have suggested that dietary fibres such as oligofructose favour the growth of 
Table 4. Biodiversity of caecal bacterial communities and relative abundance (\%) of bacterial taxa at phylum and genus level in rats fed experimental diets (analysed by MiSeq) ${ }^{1,2}$

\begin{tabular}{|c|c|c|c|c|c|}
\hline & & CEL & STA & LBH & SBH \\
\hline \multicolumn{6}{|l|}{ Alpha diversity } \\
\hline Chao1 & & 857.64 & 1112.65 & 782.52 & 862.56 \\
\hline Observed species & & 441.00 & 603.00 & 464.00 & 508.00 \\
\hline Shannon & & 4.32 & 4.72 & 3.91 & 4.13 \\
\hline Phylogenetic diversity & & 31.18 & 39.44 & 34.03 & 35.16 \\
\hline \multicolumn{6}{|l|}{ Phylum/Family/Genus } \\
\hline Actinobacteria & & $4.17^{b}$ & $4.58^{b}$ & $4.89^{a b}$ & $7.98^{a}$ \\
\hline Micrococcaceae & Rothia & 0.45 & 0.58 & 0.9 & 0.66 \\
\hline Bifidobacteriaceae & Bifidobacterium & $0.15^{b}$ & $0.12^{b}$ & $1.65^{a}$ & $2.64^{\mathrm{a}}$ \\
\hline \multirow[t]{2}{*}{ Coriobacteriaceae } & Unclassified & 2.27 & 1.5 & 1.12 & 2.7 \\
\hline & Adlercreutzia & 1.26 & 2.3 & 1.16 & 1.85 \\
\hline Bacteroidetes & & 1.48 & 7.48 & 0.30 & 1.1 \\
\hline Bacteroidaceae & Bacteroides & 0.62 & 3.77 & 0.05 & 0.37 \\
\hline \multirow[t]{2}{*}{ Porphyromonadaceae } & Parabacteroides & 0.07 & 0.38 & 0.02 & 0.04 \\
\hline & Prevotella & $0.0^{b}$ & $0.0^{b}$ & $0.01^{a}$ & $0.01^{\mathrm{a}}$ \\
\hline Rikenellaceae & Unclassified & $0.19^{a b}$ & $0.85^{a}$ & $0.04^{b}$ & $0.28^{b}$ \\
\hline S24-7 & Unclassified & 0.48 & 2.19 & 0.13 & 0.3 \\
\hline [Odoribacteraceae] & Odoribacter & 0.09 & 0.15 & 0.03 & 0.05 \\
\hline Firmicutes & & $88.02^{\mathrm{a}}$ & $81.69^{a b}$ & $62.96^{b}$ & $67.91^{\mathrm{ab}}$ \\
\hline Lactobacillaceae & Lactobacillus & $3.93^{b}$ & $6.94^{b}$ & $3.67^{b}$ & $13.49^{a}$ \\
\hline \multirow[t]{2}{*}{ Streptococcaceae } & Lactococcus & 0.89 & 1.01 & 0.71 & 0.78 \\
\hline & Streptococcus & 0.23 & 0.4 & 0.33 & 0.35 \\
\hline Turicibacteraceae & Turicibacter & 2.52 & 4.69 & 1.21 & 2.88 \\
\hline Unclassified & Unclassified & 12.62 & 9.22 & 8.81 & 8.01 \\
\hline Christensenellaceae & Unclassified & 0.18 & 0.17 & 0.06 & 0.06 \\
\hline \multirow[t]{2}{*}{ Clostridiaceae } & Other & 2.44 & 3.49 & 5.44 & 8.62 \\
\hline & Unclassified & 7.86 & 14.15 & 10.67 & 10.42 \\
\hline \multirow[t]{5}{*}{ Lachnospiraceae } & Unclassified & 5.8 & 2.53 & 1.32 & 1.44 \\
\hline & Blautia & 5.87 & 4.06 & 0.95 & 0.71 \\
\hline & Coprococcus & 0.37 & 0.35 & 0.65 & 0.33 \\
\hline & Dorea & $6.71^{\mathrm{ab}}$ & $15.04^{\mathrm{a}}$ & $0.91^{b}$ & $3.41^{b}$ \\
\hline & [Ruminococcus] & 0.23 & 0.36 & 0.42 & 0.54 \\
\hline \multirow[t]{3}{*}{ Ruminococcaceae } & Unclassified & $20.81^{a}$ & $7.34^{\mathrm{ab}}$ & $14.62^{\mathrm{ab}}$ & $4.2^{b}$ \\
\hline & Oscillospira & 0.9 & 2.43 & 1.79 & 1.9 \\
\hline & Ruminococcus & 10.45 & 4.71 & 9.00 & 7.73 \\
\hline \multirow[t]{4}{*}{ Erysipelotrichaceae } & Unclassified & 2.24 & 0.49 & 0.37 & 1.36 \\
\hline & Allobaculum & 3.23 & 2.54 & 1.61 & 0.91 \\
\hline & Coprobacillus & 0.21 & 0.27 & 0.01 & 0.32 \\
\hline & [Eubacterium] & 0.27 & 0.27 & 0.00 & 0.05 \\
\hline Verrucomicrobia & & $4.63^{b}$ & $2.45^{b}$ & $30.19^{a}$ & $21.9^{a b}$ \\
\hline Verrucomicrobiaceae & Akkermansia & $4.63^{b}$ & $2.45^{\mathrm{b}}$ & $30.19^{a}$ & $21.9^{a b}$ \\
\hline
\end{tabular}

Akkermansia in the caecum (Everard et al., 2011, 2013). The abundance of Akkermansia inversely correlates with body weight and type 1 diabetes in mice and humans (Everard et al., 2013; Santacruz et al., 2010). Therefore, increased abundance of Akkermansia by lablab bean husk feeding is expected to yield a beneficial health impact in animals. On 
the other hand, soya bean husk feeding yielded increases in acetate and lactate concentrations, possibly as a result of the enrichment of total lactobacilli, including L. acidophilus and L. reuteri, that was detected by qPCR and MiSeq analyses. These lactobacilli, particularly L. reuteri, have been found to initially utilise raffinose-family oligosaccharides, which are converted to $\alpha$-galactooligosaccharide (Texieira et al., 2012). $\alpha$-Galactooligosaccharide is presumably further utilised by other acetate and lactate producers such as bifidobacteria, as detected by the MiSeq analyses in the present study. Lactobacilli and bifidobacteria are well known for their probiotic activities, increasing in abundance in rats upon supplementation of feed with raffinose oligosaccharides (Dinoto et al., 2006) and pectic arabinogalactan (Daguet et al., 2006). Lablab bean husk feeding was also distinguished from soya bean husk feeding by its stimulatory effect on bacteria belonging to OTU 5, a member of clostridial cluster IV and the closest relative to Oscillibacter valerigienes. Relatives of Oscillibacter were found to increase in animals fed diets rich in fermentable polysaccharides such as resistant starch (Walker et al., 2011). Another distinct phenomenon in soya bean husk feeding was the increased caecal level of succinate, a precursor of propionate; this succinate may have been produced by Prevotella, a genus whose abundance increased from 0 to $0.01 \%$ on feeding with husk-supplemented diets. Therefore, in the present study, the raffinose-family oligosaccharides and/or possibly pectin contained in both types of bean husk are hypothesised to be a main cause for the observed lactogenic and bifidogenic effects, and for the increased abundance of other beneficial bacteria.

Interestingly, bacteria related to Dorea spp. (a constituent of clostridial cluster XIVa), regarded as a potentially harmful group, were not found (as assessed by the clone library) in rats fed either type of bean husk. Lower values of this group for both $\mathrm{LBH}$ and $\mathrm{SBH}$ than for STA in the qPCR assay and in the MiSeq analysis, may suggest functional improvement of the GI health of the host. Hooda et al. (2012) reported that the faecal population of Dorea is decreased in healthy men consuming soluble polysaccharides. If the same situation applies in the present study, the presence of pectic polysaccharide in both of bean husk appears to have indirectly inhibited the growth of Dorea spp. in the caecum of rats. Increased abundance of the members of clostridial cluster XIVa, including Dorea spp., has been observed in patients with irritable bowel syndrome (Rajilic-Stojanovic et al., 2011). Thus, our finding indicated that having a diet without any fibre (for example starch) can create health problems and may be a risk factor for intestinal health. Bacterial coverage in our clone library was not sufficiently wide in the present study, given the small number of sequence reads (503 in total). However, the sequences that were obtained showed changes in the clone libraries associated with the various feeding regimens; these differences were useful for focusing attention on specific groups of bacteria (Akkermansia, Dorea, etc.), thereby suggesting the development of primers for quantification of those groups. In fact, qPCR assay values for these groups corresponded well with the detection frequency of those groups in the MiSeq data.

In the present study, it is possible that there was a reduced population of opportunistic and pathogenic bacteria in the low-pH condition of the caecum, such that production of harmful fermentation products remained low as a result of the enhanced growth of beneficial bacteria such as lactobacilli and bifidobacteria. In particular, the lowered indole and skatole in the caecum of rats fed either type of bean husk might be due to fibres that regulate bacterial nitrogen metabolism (Xu et al., 2002). Additionally, the insoluble fibres are expected to adsorb these bacterial putrefactive compounds, facilitating the excretion of those products. Similar findings were obtained in a previous report (An et al., 2013), indicating that fermentable fibres (including oligosaccharides and polysaccharides) suppress the accumulation of the bacterial putrefactive compounds that are responsible for the malodour of flatus and faeces. Therefore, we hypothesise that the formation of indole and skatole in the caecum were suppressed primarily by the presence of dietary fibres in the bean husk, which provide physical features such as increased adsorption ability, acceleration of excretion, and other functional activities.

In conclusion, supplementation with bean husk promoted caecal fermentation in rats, as indicated by higher concentrations of SCFAs and lactate, and decreased accumulation of bacterial putrefactive compounds. Two types of husk were tested; both exhibited remarkable selectivity against gut bacteria. Similar bifidogenic effects and suppressive effects on Dorea spp. were found with both lablab and soya bean husks. With respect to specific effects on rat caecal microbiota, lablab bean husk stimulated the growth of A. muciniphila and Oscillibacter-related bacteria, while soya bean husk stimulated the growth of members of the Lactobacillus group, including L. acidophilus and L. reuteri. Both types of bean husk were shown to contain oligosaccharides that might enrich for these beneficial bacteria, thereby inhibiting the colonisation of the intestinal tract by potential pathogens. Therefore, either of the tested bean husk types is expected to serve as a promoter of hindgut health and could find use as a potentially functional feed ingredient for monogastric animals. For future applications, it would be advantageous to analyse the rest of the oligosaccharides in both types of bean husk, even though the variability of them is probably not so complex.

\section{Conflict of interest}

The authors have no conflict of interest to declare. 


\section{References}

An, C., Kuda, T., Yazaki, T., Takahashi, H. and Kimura, B., 2013. FLX pyrosequencing analysis of the effects of the brown-algal fermentable polysaccharides alginate and laminaran on rat cecal microbiotas. Applied and Environmental Microbiology 79: 860-866. Association of Official Analytical Chemistry (AOAC), 1990. Official Methods of Analysis, $15^{\text {th }}$ edition. AOAC, Rockville, MD, USA.

Belanche, A., Doreau, M., Edwards, J.E., Moorby, J.M., Pinloche, E. and Newbold, C.J., 2012. Shifts in the rumen microbiota due to the type of carbohydrate and level of protein ingested by dairy cattle are associated with changes in rumen fermentation. Journal of Nutrition 142: 1684-1692.

Caporaso, J.G., Kuczynski, J., Stombaugh, J., Bittinger, K., Bushman, F.D., Costello, E.K., Fierer, N., Pena, A.G., Goodrich, J.K., Gordon, J.I., Huttley, G.A., Kelley, S.T., Knights, D., Koenig, J.E., Ley, R.E., Lozupone, C.A., McDonald, D., Muegge, B.D., Pirrung, M., Reeder, J., Sevinsky, J.R., Turnbaugh, P.J., Walters, W.A., Widmann, J., Yatsunenko, T., Zaneveld, J. and Knight, R., 2010. QIIME allows analysis of high-throughput community sequencing data. Nature Methods 7: 335-336.

Cole, J.T., Fahey, G.C., Merchen Jr., N.R., Patil, A.R., Murray, S.M., Hussein, H.S., Brent Jr., J.L., 1999. Soybean hulls as a dietary fiber source for dogs. Journal of Animal Science 77: 917-924.

Collins, M.D., Lawson, P.A., Willems, A., Cordoba, J.J., FernandezGarayzabal, J., Carcia, P., Cai, J., Hippe, H. and Farrow, J.A.E., 1994. The phylogeny of genus Clostridium: proposal of five new genera and eleven new species combinations. International Journal of Systematic and Evolutionary Microbiology 44: 812-826.

Daguet, D., Pinheiro, I., Verhelst, A., Possemiers, S. and Marzorat, M., 2006. Arabinogalactan and fructooligosaccharides improve the gut barrier function in distinct areas of the colon in the simulator of the human intestinal microbial ecosystem. Journal of Functional Food 20: 369-379.

Dinoto, A., Suksomcheep, A., Ishizuka, S., Kimura, H., Hanada, S., Kamagata, Y., Asano, K., Tomita, F. and Yokota, A., 2006. Modulation of rat cecal microbiota by administration of raffinose and encapsulated Bifidobacterium breve. Applied and Environmental Microbiology 72: 784-792.

DuBois, M., Gilles, K., Hamilton, J., Rebers, P.A. and Smith, F., 1956. Colorimetric method for determination of sugars and related substances. Analytical Chemistry 28: 350-356.

Everard, A., Belzer, C., Geurts, L., Ouwerkerk, J.P., Druart, C., Bindels, L.B., Guiot, Y., Derrien, M., Muccioli, G.G., Delzenne, N.M., De Vos, W.M. and Cani, P.D., 2013. Crosstalk between Akkermansia muciniphila and intestinal epithelium controls diet-induced obesity. Proceedings of the National Academy of Sciences of the USA 110: 9067-9071.

Everard, A., Lazarevic, V., Derrien, M., Girard, M., Muccioli, G.G., Neyrinck, A.M., Possemiers, S., Van Holle, A., Francois, P., De Vos, W.M., Delzenne, N.M., Schrenzel, J. and Cani, P.D., 2011. Responses of gut microbiota and glucose and lipid metabolism to prebiotics in genetic obese and diet-induced leptin-resistant mice. Diabetes 60: 2775-2786.
Fuma, R., Oyaizu, S., Nukui, Y., Ngwe, T., Shinkai, T., Koike, S., Kobayashi, Y., 2012. Use of bean husk as an easily digestible fiber source for activating the fibrolytic rumen bacterium Fibrobacter succinogenes and rice straw digestion. Animal Science Journal 83: 696-703.

Gibson, G.R. and Roberfroid, M.B., 1995. Dietary modulation of the human colonic microbiota: introducing the concept of prebiotics. Journal of Nutrition 125: 1401-1412.

Gnanasambandam, R. and Proctor, A., 1999. Preparation of soy hull pectin. Food Chemistry 65: 461-467.

Goering, H.K. and Van Soest, P.J., 1975. Forage fiber analysis. Agricultural Research Service. Agricultural handbook No. 379. US Department of Agriculture, Washington, DC, USA.

Herlemann, D.P., Labrenz, M., Jurgens, K., Bertilsson, S., Waniek, J.J. and Andersson, A.F., 2011. Transitions in bacterial communities along the $2000 \mathrm{~km}$ salinity gradient of the Baltic Sea. ISME Journal 5: 1571-1579.

Hooda, S., Boler, B.M., Serao, M.C., Brulc, J.M., Staeger, M.A., Boileau, T.W., Dowd, S.E., Fahey Jr., G.C. and Swanson, K.S., 2012. 454-pyrosequencing reveals a shift in fecal microbiota of healthy adult men consuming polydextrose or soluble corn fiber. Journal of Nutrition 142: 1259-1265.

Htay, K.M., Moe, T.H., Khin, S.M., Aung, A., Htin, N.N. and Ngwe, T., 2014. The study of the different bean husks as the easily digestible fiber source on in vitro gas production of rice straw, urea-treated rice straw and Napier grass. Myanmar Veterinary Journal 16: 113-124.

Hussein, M.M.D., Helmy, W.A. and Salem, H.M., 1998. Biological activities of some galactomannan and their sulfated derivatives. Phytochemistry 48: 479-484.

Ipharraguerre, I.R. and Clark, J.H., 2003. Soyhulls as an alternative feed for lactating dairy cows: a review. Journal of Dairy Science 86: 1052-1073.

Karr-Lilienthal, L.K., Kadzere, C.T., Grieshop, C.M., Fahey Jr., G.C., 2005. Chemical and nutritional properties of soybean carbohydrates as related to nonruminants: a review. Livestock Production Science 97: 1-12.

Koike, S., Yabuki, H. and Kobayashi, Y., 2007. Validation and application of real-time PCR assays for representative rumen bacteria. Animal Science Journal 78: 135-141.

Monsoor, M.A., 2005. Effect of drying methods on the functional properties of soy hull pectin. Carbohydrate Polymers 61: 362-367.

Mullin, W.J. and Xu, W., 2001. Study of soybean seed coat components and their relationship to water absorption. Journal of Agricultural and Food Chemistry 49: 5331-5335.

Muralikrishna, G. and Tharanathan, R.N., 1994. Characterization of pectic polysaccharides from pulse husks. Food Chemistry 50: 87-89.

Myint, H., Kishi, H., Koike, S. and Kobayashi, Y., 2017. Effect of chickpea husk dietary supplementation on blood and cecal parameters in rats. Animal Science Journal 88: 372-378.

Ngwe, T., Nukui, Y., Oyaizu, S., Takamoto, G., Koike, S., Ueda, K., Nakatsuji, H., Kondo, S. and Kobayashi, Y., 2012. Bean husks as a supplemental fiber for ruminants: potential use for activation of fibrolytic rumen bacteria to improve main forage digestion. Animal Science Journal 83: 43-49. 
Pascoal, L.A.F., Thomaz, M.C., Watanabe, P.H., Ruiz, U.S., Amorim, A.B., Daniel, E. and Da Silva, S.Z., 2015. Purified cellulose, soybean hulls and citrus pulp as a source of fiber for weaned piglets. Scientia Agricola 72: 400-410.

Rajilic-Stojanovic, M., Biagi, E., Heilig, H.G.H.J., Kajander, K., Kekkonen, R.A., Tims, S. and De Vos, W.M., 2011. Global and deep molecular analysis of microbiota signatures in fecal samples from patients with irritable bowel syndrome. Gastroenterology 141: 1792-1801.

Rinttila, T., Kassinen, A., Malinen, E., Krogius, L. and Palv, A., 2004. Development of an extensive set of $16 \mathrm{~S}$ rDNA targeted primers for quantification of pathogenic and indigenous bacteria in faecal samples by real-time PCR. Journal of Applied Microbiology 97: 1166-1177.

Santacruz, A., Collado, M.C., Garcia-Valdes, L., Segura, M.T., MartinLagos, J.A., Anjos, T., Marti-Romero, M., Lopez, R.M., Florido, J., Campoy, C. and Sanz, Y., 2010. Gut microbiota composition is associated with body weight, weight gain and biochemical parameters in pregnant women. British Journal of Nutrition 104: 83-92.

Schloss, P.D., Westcott, S.L., Ryabin, T., Hall, J.R., Hartmann, M., Hollister, E.B., Lesniewski, R.A., Oakley, B.B., Parks, D.H., Robinson, C.J., Sahl, J.W., Stres, B., Thallinger, G.G., Van Horn, D.J. and Weber, C.F., 2009. Introducing mothur: open-source, platform-independent, community-supported software for describing and comparing microbial communities. Applied and Environmental Microbiology 75: 7537-7541.

Simpson, J.M., Martineau, B., Jones, W.E., Ballam, J.M. and Mackie, R.I., 2002. Characterization of fecal bacterial populations in canines: effects of age, breed and dietary fiber. Microbial Ecology 44: 186-197.

Suto, T., 1973. Examination of the rumen. In: Nakamura, R., Yonemura, T. and Suto, T. (eds.) Methods in the clinical examination of the bovine. Nosan Gyoson Bunka Kyokai, Tokyo, Japan, pp. 39-42.
Teixeira, J.S., McNeill, V. and Ganzle, M.G., 2012. Levansucrase and sucrose phoshorylase contribute to raffinose, stachyose, and verbascose metabolism by lactobacilli. Food Microbiology 31: 278-284.

Tungland, B.C. and Meyer, D., 2002. Nondigestible oligo- and polysaccharides (dietary fiber): their physiology and role in human health and food. Comprehensive reviews. Food Science and Food Safety 1: 90-109.

Walker, A.W., Ince, J., Duncan, S.H., Webster, L.M., Holtrop, G., Ze, X., Brown, D., Stares, M.D., Scott, P., Bergerat, A., Louis, P., Mclntosh, F., Johnstone, A.M., Lobley, G.E., Parkhill, J. and Flint, H.J., 2011. Dominant and diet responsive groups of bacteria within the human colonic microbiota. ISME Journal 5: 220-230.

Walstra, P., Claudi-Magnussen, C., Chevillon, P., Von Seth, G., Diestre, A., Matthews, R., Homer, D.B. and Bonneau, M., 1999. An international study on the importance of androstenone and skatole for boar taint: levels of androstenone and skatole by country and season. Livestock Production Science 82: 15-28.

Wang, Y., Chen, Y., Cho, J., Yoo, J.S., Huang, Y., Kim, H.J., Shin, S.O., Zhou, T.X. and Kim, I.H., 2009. Effect of soybean hull supplementation to finishing pigs on the emission of noxious gases from slurry. Animal Science Journal 80: 316-321.

Weatherburn, M.W., 1967. Phenol-hypochloride reaction for determination of ammonia. Analytical Chemist 39: 971-974.

$\mathrm{Xu}$, Z.R., Hu, C.H. and Wang, M.Q., 2002. Effects of fructooligosaccharide on conversion of l-tryptophan to skatole and indole by mixed populations of pig fecal bacteria. Journal of General and Applied Microbiology 48: 83-89.

$\mathrm{Yu}, \mathrm{Z}$. and Morrison, M., 2004. Improved extraction of PCR-quality community DNA from digesta and fecal samples. Biotechniques 36: 808-881. 